\title{
POTENSI BAHARI LASEM SEBAGAI SEJARAH MARITIM LOKAL
}

\author{
Avif Arfianto Purwoko Utomo \\ Universitas Sebelas Maret, avifapu14@gmail.com
}

\begin{abstract}
Abstrak: Artikel ini membahas tentang potensi bahari Lasem sebagai salah satu sejarah maritim lokal. Studi sejarah Indonesia lebih banyak mementingkan peristiwa yang terjadi di darat, meskipun lebih dari separuh wilayah Indonesai terdiri dari laut. Sebagai alternatif studi sejarah, terdapat kajian sejarah yang berbasis pada budaya maritim. Sejarah maritim sangatlah penting pada saat ini, karena sebagian besar wilayah Indonesia adalah laut. Salah satu kajian sejarah maritim adalah potensi bahari yang ada di wilayah Lasem. Potensi-potensi bahari Lasem sebagai sejarah maritim lokal meliputi: (1) kondisi geografis Lasem sebagai lokasi pelabuhan maritim; (2) peninggalan sejarah maritim Lasem; (3) budaya maritim masyarakat Lasem. Pemahaman tentang potensi bahari Lasem sangatlah penting bagi masyarakat. Secara garis besar, terdapat relasi antara potensi bahari Lasem dengan sejarah maritim Indonesia. Potensi bahari Lasem sebagai sejarah maritim lokal berfungsi untuk menyokong narasi sejarah nasional.
\end{abstract}

Kata-kata kunci: Potensi Bahari Lasem, Sejarah Maritim, Budaya Maritim.

\begin{abstract}
This article discusses Lasem's nautical potential as one of the local maritime history. The study of the history of Indonesiamore concerned with events that occur on land, although more than half of Indonesia's territory consists of the sea. As an alternative to historical studies, there is historical studies based on maritime culture. The history of maritime is very important at the moment, because most areas of Indonesia is the sea. One study of maritime history is the nautical potential in the Lasem region. Lasem's nautical potential as local maritime history includes: (1) the geographical conditions Lasem as a maritime port locations; (2) the maritime heritage of Lasem; (3) the maritime culture of the Lasem community. An understanding of Lasem's nautical potential is very important for the community. Broadly speaking, there is a relationship between Lasem's nautical potential with Indonesian maritime history. Lasem's nautical potential as a local maritime history serves to support the narrative of national history.
\end{abstract}

Keywords: Lasem's nautical potential, Maritime History, Maritime Culture

Kini sudah waktunya bangsa Indonesia dengan penuh kesadaran mengintrospeksi paradigma berpikir lamanya dengan mengubah orientasi agar tidak lagi hanya terfokus kepada aspek darat tapi juga memberi perhatian pada dimensi laut. Laut digambarkan sebagai suatu dunia bebas dan terbuka. Ini menjadikan sumber bagi masyarakat Indonesia untuk bisa memanfaatkan diri pada laut, baik secara langsung maupun tidak. Laut merupakan sumber daya kehidupan yang sungguh luar biasa besarnya sekaligus memiliki kekhasan tersendiri berbeda dengan sumber daya yang ada di darat. Pada dasarnya laut memberikan potensi kepada masyarakat untuk memenuhi kebutuhan seharihari. Suatu bangsa bisa menjadi besar bila kepribadiannya disesuaikan dengan alam sekitar.

Indonesia merupakan negara yang terdiri dari daratan dan lautan. Bagitu banyak pulau baik besar maupun kecil yang terhubung oleh laut, maka Indonesia juga disebut Nusantara. Dengan demikian transportasi air termasuk sarana yang 
digunakan sebagai penghubung antara pulau satu dengan yang lainnya. Keberadaan tempat berlabuh menjadi sangat penting ketika seseorang akan berkunjung ke suatu daerah tujuan, dan pelabuhan pun terbentuk untuk berbagai macam keperluan. Seperti diketahui, Nusantara adalah wilayah kepulauan di satu pihak dan wilayah perairan di lain pihak, di mana perairan merupakan 2/3 dari seluruh wilayah. Ketika masyarakat Nusantara masih terdiri atas kerajaan-kerajaan kecil yang menyebar di seluruh wilayah tersebut, ada beberapa kerajaan yang rakyatnya termasuk bangsa laut berkebaharian dan merupakan pelaut handal dari nelayan (Anshoriy Ch. Nasruddin, 2008: 8).

Sebagai negara bahari, Indonesia tidak hanya memiliki satu "laut utama" atau heart of sea tetapi paling tidak ada tiga laut utama yang membentuk Indonesia sebagai sea system yaitu Laut Jawa, Laut Flores dan Laut Banda. Laut Jawa merupakan kawasan jantung perdagangan laut kepulauan Indonesia dan telah terintegrasi oleh jaringan pelayaran dan perdagangan sebelum datangnya bangsa Barat. Bahwa sejarah dianggap penting dalam kehidupan masyarakat bangsa manapun, kiranya tidak usah diragukan. Sejarah adalah ingatan kolektif, gudang pengalaman yang menjadi sumber masyarakat depannya (Zuhdi, Susanto, 2014: 537). Indonesia telah memenuhi unsur negara maritim, kedudukan geografis sebagai negara kepulauan dan telah diakui secara internasional. Bentuk tanah dan pantainya yang sangat luas memberikan peluang bagi Indonesia untuk mendirikan banyak pelabuhan laut. Dulu laut adalah jalan hidup (way of life), karena kearifan tradisional dan pengetahuan lokal tentang laut berkembang (Satria, 2014: 99).

Pelayaran dan perdagangan di perairan Indonesia memiliki jalur yang strategis salah satunya laut Jawa. Laut Ja- wa memiliki ombak yang relatif kecil dibandingankan dengan laut lainnya yang berada di Indonesia dan sekitarnya yaitu Laut Cina Selatan, Samudera Hindia, Samudera Pasifik, dan lain sebagainya. Dengan jalur lalu-lintas perdagangan dunia. Dalam konteks ini laut Jawa berfungsi sebagai penghubung pusat dagang di sepanjang pantai yang berkembang karena pelayaran dan perdagangan melalui laut Jawa. Sejarah maritim menjadi penting karena hubungan antara komunitas dengan komunitas yang lain membuat komunikasi lewat jalur pelayaran maupun perdagangan berlangsung dengan baik. Dalam hal ini Lasem merupakan daerah pesisir pantai di utara pulau Jawa yang posisinya strategis karena sebagai jembatan jaringan pelayaran dan perdagangan.

\section{SEJARAH LASEM SAMPAI ZAMAN HINDIA BELANDA}

Pada masa kejayaan Majapahit, Lasem merupakan bagian dari wilayah kekuasaan yang dipimpin oleh Bhre. Kedudukan Bhre Lasem merupakan wakil dari raja Majapahit untuk mengawasi jalannya pemerintahan lokal. Posisi Bhre Lasem ini sangat penting, karena menjadi penanggungjawab wilayah pesisir yang menjadi bagian dari kekuasaan Majapahit. Selain itu, adanya bandar Lasem sebagai pintu utama Kerajaan Majapahit menempatkan Bhre Lasem pada posisi strategis (Aziz, 2014: 59). Dalam sejarahnya, Lasem dikenal sebagai kota Bandar, kota Pelabuhan penting sejak zaman Majapahit hingga penjajahan Jepang. Pada masa Majapahit, Lasem menjadi kerajaan kecil di bawah pemerintahan Bhre Lasem, yang juga mengangkat syahbandar untuk menjadi palang pintu kekuasaan atas arus ekonomi pelabuhan laut di kota ini (Aziz , 2014: 39). 
Pentingnya Lasem sebagai penopang kekuatan maritim Majapahit ini diperkuat lagi setelah kedatangan rombongan Laksamana Cheng Ho, seorang duta Kaisar Yung-Lo dari Tiongkok kepada Raja Wikrama Wardana pada awal abad 15 (Unjiya, 2014: 6). Dari hasil kunjungan pertama itu, Majapahit kemudian menunjuk kota-kota pelabuhan, seperti Gresik, Surabaya, Tuban dan Lasem sebagai daerah bebas pajak bagi rombongan Laksamana Cheng Ho dan juga para pedagang-pedagang dari negeri tiongkok. Dampak kedatangan Cheng Ho beberapa kali itu membawa akibat banyaknya gelombang orang-orang dari negeri Tiongkok yang kemudian menetap di Lasem. Setelah berakhirnya masa kekuasaan Bhre Lasem yang dijadikan kerajaan vassal Majapahit (1466-1468 M) yang beragama Hindu. Kerajaan Majapahit mengalami kemunduran yang disebabkan perebutan kekuasaan oleh para pemimpinnya.

Di era keruntuhan kerajaan Majapahit di akhir abad ke-15, ada satu kerajaan di Jawa yang berani membuat kerajaan baru yaitu kerajaan Demak yang beragama Islam. Hal ini juga didilakukan beberapa kerajaan vassal di pinggiran kota pesisiran yang menyatakan lepas dari kerajaan Majapahit dan menjadi negeri sendiri. Rakyat yang berada di pedalaman Jawa maupun yang berada di daerah yang dilanda konflik mengarah semua ke kota pelabuhan. Kota-kota pelabuhan seperti Gresik, Surabaya, Tuban dan Lasem, agama Islam mulai berkembang dengan pesat. Kerajaan Demak yang berorientasi pada kerajaan maritim menjalin hubungan yang baik dengan kadipaten-kadipaten tetangga yang lebih dulu merdeka, seperti Lasem, Tuban, Gresik, dan beberapa kerajaan di Jawa.

Kerajaan Lasem berubah menjadi Kadipaten Lasem di Bonang Binangun (1391 Saka atau 1469 M) di dekat Teluk
Regol, setelah setahun kekuasaan Bhre Lasem berakhir. Kadipaten Bonang Binangun, Lasem yang telah keluar dari kerajaan vassal Majapahit membuat negeri sendiri. Berdirinya kadipaten Lasem di dekat pelabuhan Teluk Regol bukan terjadi begitu saja tanpa sebab. Perpindahan tempat ini yang semula di Lasem mengarah ke Teluk Regol akibat derasnya arus perubahan dan dukungan para pedagang.

Kerajaan Pajang merupakan kerajaan pedalaman yang pertama pasca keruntuan kerajaan Majapahit pada 1545 M. Kerajaan yang agraris ini lambat laun dapat menguasai daerah pesisiran seperti kawasan pantai utara Lasem, Tuban, Gresik dan Surabaya. Dengan ini maka sarana perdagangan daerah pedalaman tetap eksis untuk memasarkan hasil alam ke daerah pesisir pantai utara. Untuk memperdagangkan hasil bumi daerah pedalaman tidak seramai dan padat pada masa kerajaan sebelumnya karena adanya monopoli perdangan. Takluknya kota-kota pesisiran ini ke dalam kerajaan Pajang akibat melemahnya daerah pelabuhan atas desakan politik ekonomi bangsa Eropa dengan memonopolinya.

Pada masa kerajaan Mataram Islam (1586 M) kadipaten Lasem termasuk dalam daerah kekuasaan kerajaan Mataram Islam. Kadipaten Lasem sebagai kota pesisiran dengan ciri khas kota bandar karena pengakuan dari kerajaan Mataram Islam yang merupakan agraris. Pelabuhan Lasem tetap eksis oleh persaingan dan monopoli perdagangan sejak kedatangan kapal-kapal dari Eopa. Semenjak bangsa Eropa datang ke Indonesia keadaan menjadi berubah, hal ini memicu peperangan antara rakyat Lasem dengan VOC yang disebut Perang Kuning pada tahun 1751 M dan perlawanan rakyat ini berakhir dengan kekalahan. Pada masa kolonial Hindia Belanda, Lasem tetap dijadikan 
pusat perdagangan dan industri di Kabupaten Rembang dengan kota pelabuhan yang ramai.

\section{POTENSI KEBAHARIAN LASEM}

Secara geografis letak Lasem sangatlah strategis untuk aktivitas perdagangan dan sebab itulah dulunya Lasem adalah jalur dan pusat perdagangan orang-orang yang datang ke pulau Jawa. Lasem adalah kota kecil yang secara administratif termasuk dalam wilayah Kabupaten Rembang, Jawa Tengah. Terletak di jalur pesisir utara Jawa, $12 \mathrm{~km}$ sebelah timur Kota Rembang. Wilayahnya berada di tengah-tengah jalur utama Pantura Semarang dan Surabaya (Unjiya, 2014: 1). Sebagai kota Bandar, Lasem memiliki sejarah yang panjang pada masa lampau juga berpengaruh kepada keadaan potensi bahari daerah ini.

Kedatangan armada yang sangat besar di bawah pimpinan Laksamana Cheng Ho ke Jawa sekitar abad ke-14-15 M menjadi duta politik dinasti Ming yang ingin membina hubungan bilateral dengan Majapahit terutama dalam bidang kebudayaan dan perdagangan. Aktivitas yang dilakukan yaitu perniagaan dan kemudian banyak yang tinggal menetap di daerah pesisir utara pulau jawa. Para imigran dari Tiongkok terbesar di pulau Jawa adalah Lasem (Lao Sam). Para pendatang mendarat di pelabuhan tua di pantai Caruban dan membangun pemukiman di sekitar. Banyak sekali pemukiman khas Tiongkok dan kelenteng yang tak jauh dari sungai Babagan Lasem (sungai Paturen) yang menjadi akses utama untuk penghubung antara laut atau pesisir dengan darat.

Belajar dari Majapahit, yang paling penting adalah keinginan dan kemampuan mengelola potensi bahari. Untuk bisa kembali menjadi kekuatan maritim yang disegani, Indonesia harus lebih mengoptimalkan potensi bahari, antara lain dengan jalur pelayaran strategis. Lasem sendiri banyak memiliki potensi-potensi yaitu kondisi geografis Lasem sebagai lokasi pelabuhan maritim, peninggalan sejarah maritim, dan budaya maritim masyarakat Lasem, sehingga memiliki potensi kebaharian Lasem sebagai berikut:

\section{KONDISI GEOGRAFIS LASEM SE- BAGAI LOKASI PELABUHAN MARITIM}

Secara geografis letak Lasem sangatlah setrategis untuk aktivitas perdagangan dan sebab itulah dulunya Lasem adalah jalur dan pusat perdagangan orang-orang yang datang ke pulau Jawa. Daerah Lasem merupakan salah satu kecamatan pesisir pantai laut Jawa dengan batas-batas wilayah seperti: (1) sebelah utara berbatasan langsung dengan laut Jawa, (2) sebelah timur berbatasan dengan kecamatan Sluke, (3) sebelah selatan berbatasan dengan kecamatan Pancur, (4) sedangkan sebelah barat berbatasan langsung dengan kecamatan Rembang, (5) sedangkan sebelah tenggara berbatasan langsung dengan kecamatan Sedan. Tidak heran jika Lasem sangat strategis untuk perdagangan dan bidang jasa, karena letaknya itulah Lasem mempunyai daya tarik tersendiri yaitu sebelah utara laut Jawa dan pesisir pantai yang luas, timur terdapat gunung Lasem serta sebelah selatan yang terdapat hutan.

Naskah Carita Sejarah Lasem dalam terjemahan yaitu Daerah Lasem Indah, damai dan makmur pada masa pemerintahan Bhre Lasem Duhitendu Dewi. Menurut Edi Winarno (dalam Karsono 1920:9) Kota Lasem Lasem keadaanya elok rupawan, indah dan sejuk, dipenuhi tananaman peneduh di sepanjang tepi jalanan. Istana keraton berdiri megah 
di Puri Kriyan. Taman sari Balekambang Kemalaputri (tempat ratu melepas lelah) terletak di sebelah tenggara keraton Lasem, penuh dengan pohon-pohon kamal-tropong (pohon asam jawa) yang tumbuh besar dan rindang. Di sepanjang delanggung (jalan atau gang) ditanami pohon sawo kecik, setiap sudut pertigaan dan perempatan jalan ditanami pohon beringin. Tiap-tiap halaman rumah penduduk ditanami pohon kelapa gading puyuh sepasang (di kiri-kanan halaman) yang buahnya lebat bergelantungan, aneka bunga ditanam.

Memiliki laut yang luas di ujung utara serta pesisir pantai yang memanjang, di sini Lasem memiliki sumber daya alam yang melimpah terutama di bidang laut. Pemanfaatan yang baik menjadikan sumber mata pencaharian masyarakat pesisir utara Lasem berprofesi sebagai nelayan. Dengan adanya ombak laut yang tenang maka tak heran banyak nelayan yang membuat kapal mereka sendiri dengan ukuran yang kecil. Perusahaan galagan kapal juga menggeliat di bidang ekonomi. Memiliki pelabuhan yang strategis cukup membuat masyarakat terbantu untuk bongkar muat barang hasil laut. Menurut Dahuri (dalam Seknas, 2014: 139), sebagai negara kepulauan terbesar di dunia, transportasi laut merupakan urat nadi kehidupan ekonomi, politik, sosial budaya, pertahaman keamanan, sarana untuk memperkokoh kesatuan dan persatuan.

Orang Jawa biasa membuat perahu dan kapal dengan baik, terutama perahu. Kapal besar bisa dibuat di distrik-distrik milik orang Eropa, sedangkan orang Jawa jarang membuat kapal besar berbentuk persegi. Pembuat kapal terbaik ada di distrik Rembang dan Gresik, tetapi pembuatan perahu dan kapal kecil dilakukan penduduk di berbagai daerah. Melihat potensi pelabuhan dan dermaga serta hutan jati yang lebat di Jawa, harapan yang tim- bul adalah pulau ini akan menghasilkan berbagai kapal dan menjadi pelabuhan perdagangan internasional terpenting (Raffles, 2008:110).

Rembang, yang sebelumnya dipimpin saudagar, tempat ini menghasilkan garam dan kayu, dan sebuah kapal berbobot 500 ton dan tiga atau empat kapal yang lebih kecil setiap tahunnya dibangun di sini untuk VOC (Stockdale, 2014:165). Dua pelabuhan penting di Lasem yaitu bandar Regol dan Kairingan dijadikan pangkalan utama kapal tempur dan kapal ekspedisi Majapahit. Tak jauh dari situ dibangun pula galangan kapal yang memproduksi kapal-kapal tempur maupun kapal-kapal niaga. Budaya maritim yang dibangun dan dikembangkan oleh Majapahit di daerah yang benar-benar mempunyai potensi kelautan yang baik.

Lasem tiap tahunnya harus menyerahkan satu kapal Pancalang yang panjangnya 11-12 vandem (satu vandem sekitar 1.69 meter), 600 balok kayu jati, 1.200 papan kayu dan enam pikul katun. Daerah Lasem terdapat sebuah tempat penampungan kayu hasil tebangan dan dua tempat pembuatan kapal, yaitu di Dasun dan Bancar. Kegiatan industri perkapalan yang dilakukan oleh penduduk juga sangat maju, misalnya pada tahun 1832 tercatat jumlah kapal atau perahu seperti berikut. Kegiatan Jumlah kapal berik 15, sekunar 15 , pancalang 8 , paduakang 2 , perahu mayang 232, prahu complang 41, dukut 102, sentek 353, jukung 346, bessi jeropian 13. Kegiatan kerajinan atau industri perkapalan itu dapat berkembang baik karena didukung adanya bahan baku kayu jati yang tersedia cukup banyak. Kelompok pengrajin atau pembuat kapal atau perahu ini merupakan kelompok penduduk yang sangat penting karena hanya dijumpai di beberapa tempat saja, dan keahliannya itu banyak dimanfaatkan oleh pemerintah Hindia-Belanda untuk 
membuat kapal-kapal (Warto, 2001: 17$50)$.

Simbol perahu memang lebih cocok untuk sebuah negara maritim seperti Indonesia. Ini sekaligus melambangkan dinamika negara dan pentingnya fungsi setiap bagian yang membentuk perahu itu serta mengharuskan pimpinannya untuk memelihara keseimbangan di dalam negeri agar perahu tidak oleng: kegiatan pembangunan yang berat sebelah tentu saja akan membahayakan keseimbangan ini. Patut diakui bahwa organisasi kapal menuntut suatu hierarki dengan disiplin yang ketat, tetapi nahkoda memerlukan kerjasama dari setiap awak kapal yang menyadari akan pentingnya kedudukan masing-masing. Demikian pula setiap bagian kapal mempunyai fungsinya yang khas yang esensial untk keselamatan berlayar. Kesadaran ini berbeda dengan anggapan negara konsentrasi yang melihat lingkaran pinggiran sebagai daerah yang ketika Mataram berangsur-angsur menyerahkan daerah pesisir kepada VOC (Chambert dan Ambary, 1999: 87).

\section{PENINGGALAN SEJARAH MARI- TIM LASEM}

Lasem memiliki sungai yang pada masa lalu menjadi urat nadi perdagangan daerah tersebut. Sungai inilah yang menghubungkan daerah pedalaman dengan daerah pesisir. Di tempat tersebut terdapat sebuah pelabuhan yang berfungsi sebagai arena keluar masuk orang dan barang baik dari daerah Lasem dan sekitarnya maupun dari daerah lain (pulau lain) yang akan ke Lasem dan sekitarnya. Akan tetapi pada masa sekarang, sungai tersebut sudah tidak dapat dilayari, hal itu karena Sungai Lasem sudah mengalami pendangkalan. Di daerah pedalaman terdapat Gunung Argopuro dan Gunung Boegel serta daerah yang dinamakan
Pamotan. Diduga akibat dari pendangkalan di muara sungai dan Laut Jawa, maka garis pantai di sekitar Lasem menjadi lebih maju ke arah laut (Handinoto, 2015:52). Sejarah telah menunjukkan bangsa Indonesia mencintai laut, dan menjadi bagian dari masyarakat maritim. Pada masa lalu menunjukkan bahwa Indonesia memiliki pengaruh yang besar terutama di bidang kekuatan maritim di Asia Tenggara. Tak heran, wilayah laut Indonesia dengan luas 2/3 lebih banyak di banding daratan. Dalam catatan sejarah terekam bukti-bukti bahwa nenek moyang bangsa Indonesia menguasai lautan besar (Setianegara, 2014: 118).

Jangkar kapal tua yang diperkirakan dari abad $14 \mathrm{M}$ diperkirakan merupakan peninggalan kapal Tiongkok dan kapal-kapal dari Majapahit yang banyak sekali ditemukan di sepanjang garis pantai Lasem adalah jangkar tua yang berada di rumah candu Lawang Ombo Dasun, jangkar kapal tua yang berada di pantai Rembang, penemuan jangkar kapal tua yang ditemukan nelayan di perairan Karang Sinden (Lasem) pada bulan Juli 2011 dengan panjang 4 meter dan lebar 3 meter, jangkat tua yang dimonumenkan di dalam tempat wisata Taman Kartini Rembang. Selain itu, telah ditemukan juga bangkai kapal purba di Ghodo Punjulharjo pada bulan Juli 2008 yang diperkirakan pada abad ke- 7-8 M.

Menurut Unjiya (20014: 62) Prasasti Karang Bogem dan Biluluk menyebutkan bahwa Lasem penghasil garam dan ikan terbesar untuk kebutuhan negeri. Prasasti ini juga mengisyaraktkan bahwa sektor produksi dan hasil pengolahan alam dikuasai oleh bangsawan yang telah menjadi saudagar besar. Penguasaan tersebut dapat dilihat dengan kedudukan Rajasa Wardhana sebagai Dampoawang (syahbandar) di pelabuhan Teluk Regol dan Kairingan. Pelabuhan-pelabuhan di 
Jawa masa Majapahit seperti terkabar dari teks Tiongkok, membebaskan kapal asing yang berlabuh maupun yang singgah dan mengharuskan kapal-kapal yang dari wilayah timur untuk singgah di Jawa. Pejabat kerajaan memungut pajak dari setiap kapal asing yang melakukan perdagangan dengan uang emas.

Di Lasem berdiri pula galangan kapal di Caruban, Sekitar pelabuhan Kairingan. Hutan-hutan wilayah Lasem yang menghasilkan kayu jati kualitas utama mempermudah pasokan untuk bahan pembuatan kapal. Kapal-kapal militer maupun niaga diproduksi di galangan kapal Caruban. Konon kapal-kapal Majapahit sangat terkenal ketangguhannya dalam menaklukkan samudera. Di perairan manapun, di penjuru Nusantara dan Asia Tenggara, kapal-kapal berbendera merah putih tersebut terlihat gagah menantang samudera dengan layarnya yang terkembang. Hingga abad ke $17 \mathrm{M}$, galangan kapal di Lasem tetap ada dan terus beroperasi (bahkan terus berlanjut pada masa Hindia Belanda abad 18-19 M yang memproduksi kapal-kapal dari bahan besi). Berita Eropa menyebutkan bahawa pada waktu itu kapal-kapal Jawa dibuat di Banjarmasin dan Lasem (Unjiya, 2014: 60-61). Adanya galangan kapal besar saat itu mengindikasikan Lasem merupakan wilayah strategis. Lasem menjadi tempat pembuatan perahu sekaligus kota-kota pelabuhan seperti halnya Rembang dan Juana, jauh sebelum kehadiran VOC di Nusantara. Lasem kaya akan hutan-hutan jati yang sangat penting untuk pembuatan perahu. Jenis-jenis perahu yang diproduksi di galangangalangan itu antara lain perahu Gonting, dan Jung yang berukuran sekitar 50 sampai 60 ton (Poesponegoro, dkk, 2008:51).

Di Kota Lasem masih terdapat bukti dengan masih adanya rumah opium peninggalan keluarga Tionghoa, di samping kelenteng $\mathrm{Cu}$ Ang Kiong, di sisi timur sungai Lasem di Desa Dasun. Rumah ini berusia lebih dari serratus tahun, dan masih menjadi bagian penting situs budaya Tionghoa di Kota Lasem. Di rumah ini, masih terdapat bekas gudang penyimpanan candu, serta sumur tua yang mngubungkan antara sebuah kamar dengan terowongan bawah tanah bantaran sungai. Cara yang di gunakan untuk memasok candu dengan memasukkannya di dalam peti mati yang di bawa dari laut melewati sungai Lasem, dan kemudian masuk ke terowongan yang menuju rumah (Aziz, 2014: 67).

\section{BUDAYA MARITIM MASYARAKAT LASEM}

Pada bidang budaya maritim, jika Indonesia secara umum ingin mendapat porsi lebih dari manfaat yang berbasis maritim, maka budaya dan sikap mentalnya terhadap maritim harus berubah. Maritim merupakan bagian integral dari identitas dan potensi kemakmuran bagi masyarakat di Indonesia. Karakter maritim yang berciri dinamis, egaliter, dan pantang menyerah terus ditumbuh-kembangkan. Apabila ini terus dilakukan secara konsisen dan berkesinambungan, bukan tidak mungkin bangsa Indonesia akan kembali menemukan jati dirinya sebagai bangsa maritim (Suropati, dkk, 2016: 199-200).

Budaya dalam arti praktis dapat dimengerti sebagai perwujudan dari sistem nilai budaya suatu masyarakat yang memperlihatkan karakter atau identitas yang tampak menyolok sehingga mudah dikenali kehadirannya. Relief perahu pada candi Borobudur menunjukkan kehidupan di laut manusia Jawa yang jauh telah berlayar dalam abad-abad sebelumnya (Zuhdi, 2014: 224). Budaya maritim adalah kumpulan tata nilai, cara pandang dan sikap hidup yang berpusat pada air sebagai 
sumber kehidupan, karena massa air di planet bumi ini kebanyakan di laut, maka budaya maritim diartikan lebih berdimensi laut terutama laut sebagai ruang kehidupan. Jika belajar adalah proses memaknai pengalaman sementara konstruksi pengalaman menyaratkan kepekaan ruang dan waktu, maka budaya maritim adalah budaya belajar (Rosyid, 2017: 165). Secara perlahan dan pasti pemahaman terhadap budaya maritim dapat diturunkan dari satu generasi ke generasi berikutnya. Doktrin kemaritiman dan pergesaran mindset dari darat ke laut dapat berjalan tanpa menyebabkan geger budaya di masyarakat. Budaya maritim secara otomatis akan menjiwai setiap gerak langkah, pola fikir dan sikap generasi bangsa di masa depan (Hendrawan, 2016: 180-181).

Sebagai kota pelabuhan, penduduk Lasem terbiasa dengan kehidupan yang terbuka dan menyambut pendatang baru. Terjadinya interaksi antara penduduk lokal dan orang-orang asing dari berbagai negeri membentuk karakter dan budaya keterbukaan dan saling menghargai. Tradisi upacara-upacara ataupun ritual adat masyarakat untuk memengucap rasa syukur kepada Tuhan atas limpahan karunia, rezeki dan hasil bumi seperti sedekah bumi ataupun sedekah laut. Di desa Dasun terdapat tradisi Larung Sesaji laut yang bertujuan untuk memberikan rasa syukur karena telah memberikan hasil laut yang melimpah serta menjaga para nelayan serta masyarakat pesisir pantai.

Luasnya pesisir pantai membuat daerah Lasem bagian utara menjadikan mata pencaharian selain menjadi nelayan juga masyarakat setempat berprofesi sebagai petani garam serta mempunyai tambak garam dan ikan yang berlimpah. Menurut Raflles (2008: 113) Proses pembuatan garam di pantai utara sangat sederhana, dengan mengandalkan penguapan dari sinar matahari, tidak seperti proses di
Bengali yang rumit. Penampungan air laut dibuat saat musim pasang, dan air dibiarkan tergenang selama beberapa hari, terutama untuk mencegah rasa pahit. Setelah itu air laut akan dialirkan melalui pipapipa kecil ke berbagai lading mirip lading padi, kemudian dibiarkan menguap oleh udara dan sinar matahari. Jika cuacanya cerah butuh waktu 5 hari untuk menguapkan, kemudian garam akan dipindah ke wadah lain dan ditimbun selama beberapa hari sebelum dibawa ke gudang penyimpanan.

Batik Lasem tidak lagi bermotif batik Mataraman, akan tetapi motif Pesisiran. Demikian juga warna kain batik Lasem, tidak lagi berwarna soga, akan tetapi sudah ada pengaruh warna batik pesisiran yakni warna-wara yang terang. Masuknya pengaruh Tionghoa di Lasem berpengaruh pada motif serta penggunaan warna. Batik Lasem memiliki warna batik yang sangat khas, yaitu warna merah menyala atau dikenal dengan getih pitik (darah ayam) (Heck, 2006: 47-55). Motif batik daerah pesisir mendapat pengaruh kuat dari motif Tiongkok. Misalkan motif naga (liong, dari Bahasa Tiongkok, long), motif swastika (banjil), motif awan Tiongkok yang mudah dikenali dengan pinggir yang sejajar dengan warna terdegradasi (motif awan mendung, mega mendung), atau motif kebun (tamansari), dengan tumbuh-tumbuhan di atas warna dasar cerah dan dipenuhi wadasan yang ditarik ke atas. Silang budaya ini juga tampak pada motif batik Lasem berupa motif latohan (gangang laut) dan motif watu wadas (krikil).

\section{KEBAHARIAN LASEM SEBAGAI SEJARAH MARITIM LOKAL}

Pengalaman sejarah Indonesia menunjukkan bahwa hidup dan kehidupan bangsa ini mempunyai hubungan yang 
erat dengan keadaan dan kebijaksanaan politik dan ekonomi mancanegara di tingkat internasional. Dalam perjalanan sejarahnya bangsa Indonesia pernah mengalami kejayaan dalam bidang maritim. Pentingnya menemukan kembali (reinventing) Indonesia dengan kelautan. Kata reinventing menunjukkan bahwa ada sesuatu yang telah hilang dan harus ditemukan lagi. Yang hilang adalah kesadaran bahwa bangsa kita adalah bangsa bahari yang dulu pernah jaya. Karena itu menemukan kembali Indonesia berarti menemukan kembali identitas kebaharian sebagai identitas bangsa.

Kebaharian Lasem sangat penting dan erat kaitannya dengan pengembangan identitas masyarakat, sebab hal-hal yang sifatnya lokal sangat dekat dengan konteks daerah. Ikatan daerah di samping kedekatan dengan kultural dan emosional dalam kehidupan sehari-hari inilah kiranya yang akan memudahkan upaya untuk memahami nilai setempat dengan lebih baik. Pembangunan budaya maritim Indonesia harus menghargai dan mengembangkan kebhinekaan. Kebaharian Lasem sebagai sejarah maritim adalah kesatuan utuh dan saling behubungan dari potensi yang dimiliki laut dan kelautan serta kemampuan negara bersama masyarakat mengelola dan memanfaatkan potensi tersebut secara berdaulat dengan menghormati tradisi lokal bagi kemakmuran rakyat Indonesia. Tantangan bagi pembangunan budaya maritim adalah bagaimana masyarakat maritim dapat terlibat atau turut serta dalam pengambilan keputusan bagi pengembangan dunia kemaritiman.

Masyarakat harus tahu arti pentingnya kesadaran lingkungan maritim. Hal ini diperlukan sebab memiliki rasa bangga akan potensi bahari Lasem sebagai daerah pesisisr utara Jawa yang erat kaitannya dengan pelabuhan sebagai penghubung. Rasa bangga tersebut akan mengarahkan masyarakat untuk lebih peduli terhadap kemaritiman Indonesia. Peran inilah yang mendorong masyarakat Indonesia untuk kembali kepada yang seharusnya yaitu sebagai bangsa maritim.

\section{PENUTUP}

Pemahaman tentang sejarah maritim sangat penting dalam menjaga dan mengelola sumber daya kekayaan alam. Sejarah maritim memberikan kajian yang luas mengenai komunikasi lintas budaya antara satu komunitas dengan komunitas yang lain. Sebagai kota pelabuhan pesisir pantai utara Jawa, Lasem memiliki sejarah yang panjang serta memiliki potensi kebaharian yang di kembangkan secara baik dan benar pada dahulu kala sehingga dapat memenuhi tuntutan perkembangan industri dan mampu memberikan kesejahteraan rakyat. Setiap masyarakat memiliki sistem tersendiri sebagai pedoman, dalam potensi kebaharian Lasem terdapat beberapa hal yang berperan menopang sejarah maritim mengenai kondisi geografis Lasem sebagai lokasi pelabuhan maritim, peninggalan sejarah maritim Lasem, budaya maritim masyarakat Lasem. Hal tersebut dibuktikan dengan Lasem sebagai kawasan pelabuhan yang ramai karena berada di jalur perdagangan internasional. Pemahaman tentang potensi bahari Lasem sangatlah penting bagi masyarakat. Secara garis besar, terdapat relasi antara potensi bahari Lasem dengan sejarah maritim Indonesia. Potensi bahari Lasem sebagai sejarah maritim lokal berfungsi untuk menyokong narasi sejarah nasional.

\section{DAFTAR RUJUKAN}

Anshory, Nasrudin, dkk. 2008. Negara Maritim Nusantara: Jejak Sejarah yang Terhapus. Yogyakarta: Tiara Wacana. 
Aziz, M. 2014. Lasem Kota Tiongkok Kecil: Interaksi Cina, Arab, dan Jawa dalam Silang Budaya Pesisiran. Yogyajarta: Ombak.

Chambert-Loir, H dan Ambary, H. M. 1999. Panggung Sejarah. Jakarta: Yayasan Obor Indonesia.

Handinoto. 2015. Lasem Kota Tua Bernuansa Cina Di Jawa Tengah. Yogyakarta: Ombak.

Heck, I.F. \& Rudolf G. Smend. 2006. Batik: 75 Selected Masterpieces: The Rudolf G. Smend Collection. North Clarendon: Tuttle Publishing.

Hendrawan, D. 2016. Tantangan Kedaulatan Pangan Maritim. Jakarta: Lembaga Ketahanan Nasional Republik Indonesia.

Lapian, A.B. 2011. Orang Laut Bajak Laut Raja Laut. Depok: Komunitas Bambu. (Cetakan Ke-9).

Nurhajarini, D. R., et.al. 2015. Akulturasi Lintas Zaman Di Lasem Perspektif Sejarah dan Budaya (Kurun Niaga-Sekarang). Yogyakarta: Balai Pelestarian Nilai Budaya (BPNB).

Poesponegoro, M. D. dan Notosusanto, N. 2008. Sejarah Nasional Indonesia: Kemunculan Penjajahan di Indonesia, \pm 1700 1900, Jilid IV. Jakarta: Balai Pustaka.

Raffles, T.S. 2008. The History of Java.Yogyakarta: Penerbit Narasi.

Rosyid, D. M. 2017. Paradigma Pengembangan Maritim dan Energi. Malang: Intrans Publishing.
Satria, A. 2015. Politik Kelautan Dan Perikanan. Jakarta: Yayasan Pustaka Obor Indonesia.

Seknas. 2014. Jalan Kemandirian Bangsa. Jakarta: Gramedia Pustaka Utama.

Setianegara, H. 2014. Strategi Maritim Pada Perang Laut Nusantara Dan Poros Maritim Dunia. Yogyakarta: Leutika Prio.

Stockdale, J. J. 2014. The Island Of Java. Yogyakarta: Penerbit Indoliterasi.

Suropati, U., et.al. 2016. Arungi Samudra Bersama Sang Naga Sinergi Poros Maritim Dunia Dan Jalur Sutra Maritim Abad $\mathrm{Ke}$-21. Jakarta: Kompas Gramedia.

Tim Peneliti Balar, 2011. "Identifikasi Potensi Sumber Daya Arkeologi di Kecematan Lasem, Kabupaten Rembang, Jawa Tengah" Laporan Penelitian Arkeologi, Balai Arkeologi Yogyakarta.

Unjiya, A. 2014. Lasem Negeri Dampoawang. Yogyakarta: Salma Idea.

Warto. 2001. Blandong Kerja Wajib Ekploitasi Hutan di $\mathrm{Ka}$ risidenan Rembang Abad Ke-19. Surakarta: Pustaka Cakra.

Winarno, E. 2016. Carita Sejarah Lasem. Rembang: Kantor Perputakaan dan Arsip Kabupaten Rembang.

Zuhdi, S. 2014. Nasionalisme Laut Dan Sejarah. Depok: Komunitas Bambu. 